\title{
Erişkinlerde pes planus
}

\section{Flatfoot in adults}

\author{
Tahir Öğüt ${ }^{1}$, Necip Selçuk Yontar ${ }^{2}$ \\ 1'̇stanbul Üniversitesi, Cerrahpaşa Tıp Fakültesi, Ortopedi ve Travmatoloji Anabilim Dalı \\ ${ }^{2}$ Rize Devlet Hastanesi
}

Erişkin pes planus; iskelet matüritesinin tamamlanması sonrasında devam eden veya ortaya çıkan ve mediyal longitudinal arkta yükseklik kaybı ile karakterize bir durumdur. Mevcut deformite ağrı, instabilite ve ciddi fonksiyonel kısıtlılıklar yaratabileceği gibi herhangi bir şikayete de neden olmayabilir. Daha çok posterior tibial tendonun dejenerasyonu sonucu oluştuğundan literatürde çoğu kez "tibialis posterior tendon yetmezliği" veya "erişkin edinilmiş pes planus" olarak da geçer.

Etiyolojide esnek pes planus, tibialis posterior tendon disfonksiyonu, travma, artritler, iyatrojenik deformite, nöropatik artropatiler (Charcot), nöromusküler hastalıklar ve tarsal koalisyon gibi nedenler bulunabilir.

Asemptomatik hastalarda herhangi bir tedaviye gereksinim yoktur. Bunun yanında semptomatik hastalarda ilk basamakta aktivite modifikasyonları, germe egzersizleri, manipülasyonlar, seri alçı uygulamaları, kilo verme, ağrı ile enflamasyona yönelik ilaç kullanımı, ayakkabı değişiklikleri, ayakkabı modifikasyonları, ayak veya ayak bileği ortezleri gibi konservatif tedavilerin kullanımı bulunmaktadır. Konservatif tedaviye yanıt alınamayan hastalarda altta yatan deformitenin nedeni ve şiddetine göre sinovektomi, tendon tamiri veya tendon transferi gibi yumuşak doku prosedürleri, kalkaneusa yönelik lateral kolon uzatma veya mediyalizasyon osteotomileri, mediyal kuneiform osteotomileri, artroereisis veya eklem dejenerasyonu gelişen hastalarda ise ikili veya üçlü artrodezler uygulanabilir.

Anahtar sözcükler: erişkin; düztaban; posterior tibial tendon disfonksiyonu

\section{TANIM}

Erişkin pes planus; iskelet matüritesinin tamamlanması sonrasında devam eden veya ortaya çıkan ve mediyal longitudinal arkta yükseklik kaybı ile karakterize bir durumdur. ${ }^{[1]}$ Mevcut deformite ağrı, instabilite ve ciddi fonksiyonel kısıtlılıklar yaratabileceği gibi herhangi bir şikayete de neden olmayabilir. Daha çok posterior tibial tendonun (PTT) dejenerasyonu sonucu oluştuğundan literatürde çoğu kez "tibialis posterior tendon yetmezliği" veya "erişkin edinilmiş pes planus" olarak da geçer.
Adult flatfoot can be defined as loss in the height of medial longitudinal arch and it either persists or develops after skeletal maturity. Existing deformity can cause pain, instability and significant functional limitations or can be asymptomatic. This situation is usually called as "posterior tibial tendon dysfunction" or "adult acquired flat foot deformity" because it is mostly seen as a result of posterior tibial tendon degeneration.

Flexible flatfoot, posterior tibial tendon dysfunction, trauma, arthritis, iatrogenic deformity, neuropathic arthropathies (Charcot), neuromuscular diseases and tarsal coalition can be listed in the etiology.

Asymptomatic patients do not need treatment. Conservative treatment is the first choice in symptomatic patients; activity modifications, strechting exercises, manipulations, serial casting, weight loss, medical treatment for pain and inflamation, shoe change or modifications, use of orthoses can be listed as conservative treatment modalities. Patients who are still symptomatic after conservative treatment are candidates for surgical treatment and soft tissue procedures (synovectomy, tendon repair or tendon transfer) or bony procedures (lateral column lengthening or medialization osteotomies for calcaneus, medial cuneiform osteotomies, arthroereisis, double or triple arthrodesis in cases with joint degeneration) can be used according to the cause and severity of the deformities.

Key words: adult; flatfoot; posterior tibial tendon dysfunction

\section{KLINIK VE RADYOLOJIK BULGULAR} \section{Klinik bulgular}

Pes planus ayakta normal mediyal longitudinal arkın kaybı olarak tanımlanır ancak pes planusu olan hastalardaki tek patoloji mediyal longitudinal ark yüksekliğindeki azalma değildir. Topukta valgus diziliminin izlenmesi, subtalar ve talonaviküler eklemlerde subluksasyon, ayak önünün ayak arkasına göre supinasyonu ve kalkaneusun subtalar eklem seviyesinde eversiyonu yanında midtarsal eklem seviyesinde de abduksiyonu görülebilecek diğer değişikliklerdendir.

- İletişim adresi: Prof. Dr. Tahir Öğüt, İstanbul Üniversitesi, Cerrahpaşa Tıp Fakültesi, Ortopedi ve Travmatoloji Anabilim Dalı, 34303, Kocamustafapaşa, İstanbul. Tel: 0532 - 2941106 e-posta: drtahirogut@gmail.com

- Geliș tarihi: 16 Eylül 2013 Kabul tarihi: 21 Kasım 2013 
Bunların yanı sıra ayağa arkadan bakıldığında normalde yalnızca beşinci parmak izlenebilirken, planovalgusu olan bir ayakta daha fazla parmak izlenebilir. "Too many toes" (çok fazla parmak) bulgusu olarak tanımlanan bu durum deformitenin derecesinin belirlenmesinde yardımcl olabilir.

Ayrıca, hastanın tek ilgili ayağı üzerinde dururken arka arkaya 5-6 kez parmak ucuna kalkamaması veya ağrı nedeniyle çok zorlanması da PTT yetmezliği için patognomonik bir bulgudur.

\section{Direkt radyografi}

Radyolojik değerlendirmede standart olarak ayakta iken çekilmiş anterior-posterior (AP), lateral ve ayrıca oblik görüntüler kullanılır. Ayak bileğinde valgus deformitesinin izlenmesi durumunda bunlara ayak bileği grafileri de eklenmelidir.

Lateral radyografilerde lateral talokalkaneal açı, talusbirinci metatars açısı, talohorizontal açı ve kalkaneal pitch açıları; AP grafilerde ise talus-birinci metatars açısı, talokalkaneal açı ve talonaviküler örtüm açıları kullanılarak pes planusun radyografik değerlendirilmesi yapılır. ${ }^{[2]}$

- Lateral talokalkaneal açı: Arka ayak diziliminin bir ölçüsüdür ve arka ayakta ekin deformitesi veya varus açılanması olması ya da ayağın dorsifleksiyonda olması durumunda azalırken, arka ayağın valgus açılanmasında olması durumunda bu açı artar.

- Lateral talus-birinci metatars açısı (Meary açısı): Talus ve birinci metatarsın uzun aksları arasındaki açıdır ve ön ayağın veya arka ayağın diziliminin lateral radyografiler ile değerlendirilmesine imkan verir. Normal mediyal ark, talus aksının birinci metatars aksı ile aynı olması olarak tanımlanmış olmakla birlikte, kavus deformitesi olan bir ayakta deformite şiddetlendikçe talusbirinci metatars açısı giderek negatifleşirken, pes planusu olan bir ayakta bu açı pozitifleşir.

- Talohorizontal açı talusun uzun aksının yer düzlemi ile yaptığı açıdır ve talusun inklinasyonu hakkında bilgi verir.

- Kalkaneal pitch açısı kalkaneusun yer düzlemi ile yaptığı açıdır ve arka ayağın dizilimi hakkında bilgi vermekle beraber mediyal ark yüksekliğinin bir ölçüsü olarak da kullanılmıştır. Kavus deformitesi ile kalkaneal pitch açısı artarken, pes planusta açı azalır.

- Talonaviküler örtüm açısı naviküler kemiğin subluksasyon miktarının ölçüsüdür. AP grafilerde talusun eklem yüzeylerinin kenarından çizilen çizgiye orta noktasından bir dik çizilir. Naviküler kemiğin eklem yüzeyinin kenarından geçen ikinci hatta bir dik çizilir ve bu iki dik çizgi arasındaki açı talonaviküler örtüm açısını verir.

- AP talokalkaneal açı talusun uzun aksı ile kalkaneusun lateral kenarı arasındaki açıdır ve ayakta çekilen AP radyografiler ile değerlendirilir. Bu açı arka ayağın dizilimini yansıtır. Arka ayak varusu ile açı azalırken, arka ayağın valgus diziliminde olması açının yüksek olarak ölçülmesine neden olur.

- AP grafilerde değerlendirilen talus-birinci metatars açısı ise ön ayağın arka ayağa göre olan pozisyonunu yansıtır. Talus ile birinci metatars uzun aksları arasındaki açıdır.

Tarsal koalisyon açısından değerlendirme yapılırken ise radyografilerde koalisyonun kendisi veya koalisyona sekonder özellikler görülebilir. Mediyal oblik grafi kalkaneonaviküler koalisyonu göstermede kullanilırken, lateral grafide orta faset koalisyonu izlenebilir. Direkt grafilerde izlenebilecek ikincil değişiklikler arasında talar gagalaşma, halo veya $C$ bulgusu, lateral talar proseste genişleme veya yuvarlaklaşma, posterior subtalar eklemde daralma bulunur.

\section{Bilgisayarlı tomografi (BT), manyetik rezonans (MR) incelemeleri ve diğerleri}

Fibröz veya kartilajinöz tarsal koalisyonlar direkt radyografilerde görüntülenemezler. Bu nedenle tarsal koalisyondan şüphe edilmesi durumunda BT veya MR taramaları tanıya yardımcı olabilirler. BT koalisyonun kendisi dışında, koalisyonun büyüklüğü ve koalisyona ikincil gelişebilecek dejeneratif eklem hastalıkları konusunda da bilgi verebildiğinden dolayı tarsal koalisyonların incelenmesinde altın standart olarak kabul edilmektedir. ${ }^{[3]}$

MR inceleme; fibröz tarsal koalisyonların tanısında kullanılabileceği gibi tibialis posterior veya peroneal tendonlardaki patolojilere ikincil gelişmiş olan pes planusun tanısının konulması amacıyla kullanılabilir. ${ }^{[4]}$ Aynı zamanda spring ligamanın sağlamlığı konusunda fikir verir. Tendon patolojilerinin tanısında ultrason incelemeleri de kullanılabilir. Bunun yanında enfeksiyon veya tümör gibi altta yatan patolojilere ikincil pes planus gelişiminden şüphe edilmesi durumunda patolojilerin tanımlanması amacıyla kemik sintigrafilerine de başvurulabilir.

\section{ETIYOLOJi}

Erişkinlerde pes planus izlenmesi durumunda etiyolojide esnek pes planus, ${ }^{[5]}$ PTT disfonksiyonu, ${ }^{[6]}$ travma, ${ }^{[7]}$ artritler, ${ }^{[8]}$ iyatrojenik deformite, ${ }^{[9]}$ nöropatik artropatiler (Charcot), ${ }^{[10]}$ nöromusküler hastalıklar ${ }^{[5]}$ ve tarsal koalisyon ${ }^{[11]}$ gibi nedenler bulunabilir. 


\section{Esnek pes planus}

Erişkin popülasyonda esnek pes planus ile sık karşılaşılır ve bu durum genellikle pediatrik pes planusun sebat etmesi sonucunda görülür. ${ }^{[5]}$ Olguların büyük çoğunluğu asemptomatiktir; ancak postüral şikayetler yanında ayakta veya bacakta ağrı ya da güçsüzlük izlenebilir. ${ }^{[1]}$ Şikayetler yürüme, koşma gibi yük taşıyıcı aktiviteler sonrasında artabilir.

Pes planustaki esneklik subtalar eklemdeki hareket ile değerlendirilir. Yük taşımadığı esnada subtalar eklemin valgustan nötral pozisyona gelmesi ve longitudinal arkın izlenmesi durumunda esnek pes planustan bahsedilir. ${ }^{[12]}$ Bu durum ilk olarak Jack tarafindan tarif edilen ve ardından Hicks tarafindan açıklanan başparmak kaldırma testi (toe-raising test) ile de ortaya konabilir. $[13,14]$

Muayene esnasında sinüs tarsi, talonaviküler eklem, plantar ark, posterior tibial tendon (PTT) ve tibia alt ucunda hassasiyet tespit edilebilir.

\section{PTT disfonksiyonu}

Erişkinlerde edinilmiş düztabanlığın en sık nedeni PTT'nin tendinopatisidir. Tibialis posterior tendinopatisinin etiyolojisinde inflamatuvar sinovit, dejeneratif rüptür, tekrarlayan mikrotravma, kollajen bozuklukları, damarsal patolojiler ${ }^{[5,15]}$ ve nadiren ayak bileği kırığı, ${ }^{[16]}$ ayak bileği distorsiyonu[17] veya direkt darbe sonrasında PTT rüptürü[ ${ }^{[18]}$ gibi akut travmalar yer alır. Bunun yanında hipertansiyon, diabetes mellitus, tendon etrafına uygulanan steroid enjeksiyonları da tanımlanmış risk faktörleri arasındadır. ${ }^{[19]}$

Tendinopatinin erken dönemlerinde şikayetler ayak bileği posteromediyalinde ağrı ve şişliktir. ${ }^{[20]}$ Bu dönemde hastalar özellikle artan fiziksel aktiviteler sonrasında yürümede güçlükten şikayet ederler. Tendinopatinin ilerlemesi ile birlikte fonksiyonel kayıplar ve ilerleyici şekil bozuklukları yanında tek ayak üzerine kalkmada zorlanma ortaya çıkmaya başlar. ${ }^{[19]}$ Sonrasında daha önce ayak bileği mediyalinde hissedilmekte olan ağrı subfibular impingement (sıkışma) nedeniyle ayak bileği lateraline doğru kayar. ${ }^{[21]}$

\section{Tibialis posterior tendinopatisinde sınıflama}

Tibialis posterior tendinopatisi dört evrede değerlendirilir. Bu sınıflama sistemi Johnson ve Strom tarafından geliştirilmiş olup, dördüncü evre sonradan Myerson tarafından eklenmiştir. ${ }^{[22]}$ Evre I'de tibialis posterior üzerinde hassasiyet ve paratendonit bulguları vardır; deformite izlenmez. Evre II hastalıkta, hastalarda dinamik veya esnek düztabanlık izlenir. Ark genişlemiştir ve ön ayakta abduksiyon ve arka ayakta valgus dizilimi görülür. Evre II, ayak bileği lateralinde ağrının olup olmamasına bağlı olarak Evre IIA ve Evre IIB olarak iki ayrı gruba ayrılmıştır. Evre IIA ayak arkası mediyalinde ağrı, ödem ve PTT boyunca hassasiyet ile karakterizedir. Evre IIB olan hastalarda, artan ağrı yanında mevcut deformiteler daha ilerlemiş olarak izlenir. ${ }^{[1]}$ Evre III'e geçildiğinde arka ayaktaki valgus deformitesi sabit hale gelmiştir, buna genellikle ön ayakta kompansatuvar varus dizilimi eşlik eder. Myerson tarafından tanımlanmış olan Evre IV'te ise ayak bileği ekleminin mortis içerisinde valgus dizilimi ile birlikte lateral tibio-talar artritin eşlik edebileceği deltoid bağ yetmezliği izlenir (Tablo 1). ${ }^{[23]}$

Johnson ve Strom tarafından geliştirilen bu sınıflama, hastalığı lineer bir süreç olarak tanımlaması ve ayak arkası, ayak bileği ve orta ayakta mevcut olan deformitelerin ayrı ayrı değerlendirilmesine izin vermemesi nedeniyle eleştirilmektedir. ${ }^{[24]} \mathrm{Bu}$ aşamada Raikin ve arkadaşları tarafından geliştirilen RAM sınıflaması karşımıza çıkar. RAM sınıflamasında ayak, ayak arkası, ayak bileği ve orta ayak olarak üç bölüme ayrılır ve her bölüm deformiteler açısından ayrı ayrı değerlendirilerek kendi içerisinde toplamda altı alt sınıfa daha ayrılır. Ayak arkasındaki deformite Evre IA'da tenosinovit ile başlayıp

Tablo 1. Myerson'a göre tibialis posterior tendinopatisi sınıflaması

\begin{tabular}{clll}
\hline Evre & Klinik bulgular & Radyografik bulgular & Tendon patolojisi \\
\hline I & $\begin{array}{l}\text { Arka ayak medialinde ağrı } \\
\text { Normal ark yüksekliği } \\
\text { Normal hareket açıklığı }\end{array}$ & Normal radyografi & Tenosinovit \\
II & Tendon boyunca ağrı & $\begin{array}{l}\text { Medial ark yüksekliğinde kayıp } \\
\text { Peritalar subluksasyon } \\
\text { Talus - 1. metatars açısı gibi açısal parametrelerde bozulma }\end{array}$ & Tendonda bozulma veya rüptür \\
III & $\begin{array}{l}\text { Rijid pes planus } \\
\text { Arka ayak lateralinde ağrı }\end{array}$ & $\begin{array}{l}\text { Evre II değişikliklere ilave olarak ayak arkasında artroz ve } \\
\text { dejeneratif değişiklikler }\end{array}$ & Evre II ile aynı \\
IV $\begin{array}{l}\text { Evre III yanında ayak bileği ağrısı } \\
\text { ve subluksasyon }\end{array}$ & $\begin{array}{l}\text { Evre III değişiklikler yanında ayak bileği valgusu ve } \\
\text { dejenerasyon }\end{array}$ & Evre II ve Evre III ile aynı
\end{tabular}


evre IIIB'de üçlü artrodez ile düzeltilemeyecek derecede ileri fikse/artritik planovalgus deformitesine kadar ilerler. Ayak bileğinde nötral dizilimin bulunması Evre IA olarak değerlendirilirken, tibia alt uç lateralinde kemik kaybına ikincil valgus deformitesi Evre IIIB olarak değerlendirilir. Aynı şekilde ayak ortasında nötral dizilimin olması Evre IA iken, Evre IIIB'de ayak ortasında mediyal ve orta kolonlarda artritik değişiklikler izlenir. Yazarlar bu sınıflamanın avantajı olarak her bölgedeki deformitenin kendi başına değerlendirilmesi yoluyla hastaya özel bir tedavinin planlanabileceğini göstermektedirler.

\section{Travma}

Ayak bileği kırık-çıkıkları, kalkaneus kırıkları, talus boyun kırıkları, Lisfranc kırık-çıkıkları ve ayak arkası ya da ayak ortasında görülen diğer kırık-çıkıklar sonrasında post-travmatik pes planus gelişimi izlenebilir. ${ }^{[25]} \mathrm{Bu}$ hastalarda semptomların ciddiyeti altta yatan nedene ve hastanın aktivite seviyesine göre değişiklik gösterebilir. Biz kendi pratiğimizde atlanmış eski Lisfranc kırıkçıkıklarına bağlı yıllar sonra gelişen düztabanlıkları sık görmekteyiz.

\section{Artritler}

Romatoid artrit gibi altta yatan hastalıkların olması durumunda da pes planus izlenebilir. ${ }^{[8]}$ Bu hastalarda pes planus gelişimi daha yavaş olur ve deformite ile ağrı ilerleyici bir şekilde ortaya çıkar.

\section{5. İyatrojenik deformite}

İyatrojenik pes planus; pes equinovarus, pes kavus, metatarsus adduktus, pes planovalgus gibi deformitelerin yetersiz veya fazla düzeltilmesi sonrasında ortaya çıkabilir.

\section{Nöropatik artropati (Charcot ayağı)}

Charcot ayağı periferik nöropati ile ilişkili bir patoloji olup, patolojik kırıklar, eklem dislokasyonu ve normal ayak yapısında belirgin bir kayıp ile karakterizedir. Bu durumun en sık nedeni diabetes mellitus olmakla beraber; sifiliz ve alkolizm gibi daha az rastlanan nedenleri de bulunmaktadır. ${ }^{[10]}$

Charcot ayağı genellikle uzun süreli diyabeti yanında periferik nöropatisi de olan hastalarda görülür. ilerleyici bir deformiteye neden olur ve deformiteye bağlı olarak ülserasyonlar ve osteomiyelit gelişimi de klinik tabloya ilave olabilir.

\section{Nöromusküler Hastalıklar}

Ayak kaslarında zayıflık veya hiperaktiviteye neden olan durumlar sonrasında nörovasküler pes planus izlenebilir. Konjenital veya kalıtımsal hastalıklara ikincil, serebrovasküler hadiseler sonrasında, post-travmatik veya iyatrojenik kaynaklı olabilir. ${ }^{[1]}$

Tipik olarak yürümede anormallik, ekstremite anomalileri ve anormal nörolojik bulgular ile birliktelik gösterir.

\section{Tarsal Koalisyon}

Tarsal koalisyon genellikle çocukluk çağında rijid pes planus araştırılırken tanı alır, ancak hastaların bir kısmı erişkin çağa kadar asemptomatik kalabilirler. Genel insidansı tam olarak bilinmemekle beraber \%1 ile \%3 arasında olduğu tahmin edilmektedir. ${ }^{[26]}$ Erişkin dönemde ise insidental olarak veya hastaların semptomatik hale gelmeleri sonrasında tanı alabilir. Erişkinlerde tarsal koalisyon ile ilişkili olabilecek bulgular arasında sinus tarsi ağrısı, peroneal spazma veya ağrılı pes planus deformitesi bulunabilir.

Tablo 2. Raikin ve arkadaşlarına göre RAM sınıflaması

\begin{tabular}{|c|c|c|c|}
\hline Evre & Ayak arkası (R) & Ayak bileği (A) & Orta ayak (M) \\
\hline la & TP tendinosinoviti & Nötral dizilim & Nötral dizilim \\
\hline $\mathrm{Ib}$ & TP tendoniti & $<5^{\circ}$ valgus dizilimi & $\begin{array}{l}\text { Orta ayakta hafif, esnek } \\
\text { supinasyon }\end{array}$ \\
\hline Ila & $\begin{array}{l}\text { Esnek planovalgus } \\
\text { ( } \% 40 \text { talonaviküler örtüm) }\end{array}$ & Deltoid yetmezliği yanında valgus dizilimi & $\begin{array}{l}\text { Radyografik instabilite olmaksızın } \\
\text { orta ayakta supinasyon }\end{array}$ \\
\hline IIb & $\begin{array}{l}\text { Esnek planovalgus } \\
\text { ( } \% 40 \text { talonaviküler örtüm) }\end{array}$ & $\begin{array}{l}\text { Deltoid yetmezliği yanında valgus dizilimi ve tibio-talar } \\
\text { artrit }\end{array}$ & $\begin{array}{l}\text { Orta ayak instabilitesi ile birlikte } \\
\text { orta ayakta supinasyon }\end{array}$ \\
\hline IIIa & $\begin{array}{l}\text { Fikse/artritik planovalgus } \\
\text { (>\%40 talonaviküler örtüm) }\end{array}$ & $\begin{array}{l}\text { Distal tibia lateralinde kemik kaybına ikincil valgus } \\
\text { (deltoid normal) }\end{array}$ & $\begin{array}{l}\text { Naviküler - mediyal küneiform } \\
\text { veya } 1 . T M T \text { eklemlerde izole } \\
\text { artritik değişiklikler }\end{array}$ \\
\hline IIIb & $\begin{array}{l}\text { Fikse / artritik planovalgus } \\
\text { (<\%40 talonaviküler örtüm) }\end{array}$ & $\begin{array}{l}\text { Distal tibia lateralinde kemik kaybına ikincil valgus } \\
\text { (deltoid yetmezliği ile birlikte) }\end{array}$ & $\begin{array}{l}\text { Mediyal ve orta kolonda artritik } \\
\text { değișiklikler }\end{array}$ \\
\hline
\end{tabular}




\section{TEDAVi}

Asemptomatik hastalarda herhangi bir tedaviye gereksinim yoktur. Bunun yanında semptomatik hastalarda ilk basamakta uygulanabilecek konservatif tedavi seçenekleri arasında aktivite modifikasyonları, germe egzersizleri, manipülasyonlar, seri alçı uygulamaları, kilo verme, ağrı ile enflamasyona yönelik ilaç kullanımı, ayakkabı değişiklikleri, ayakkabı modifikasyonları, ayak veya ayak bileği ortezleri kullanımı bulunmaktadır. ${ }^{[27]}$

Aktivite modifikasyonu, buz uygulamaları ve steroid olmayan antiinflamatuvar ilaçların kullanımı özellikle aşırı kullanmaya bağlı ağrı şikayeti olan hastaların yanı sıra ileri derecede deformitesi olan hastalarda da faydalı olur.

Konservatif tedaviye dirençli olgularda uygulanacak cerrahiye pes planusun etiyolojisine bağlı olarak karar verilir.

\section{Tibialis posterior tendinopatisinde cerrahi seçenekler}

Evre I PTT disfonksiyonunun tedavisinde sinovektomi öncelikli tedaviyi oluşturur. ${ }^{[1,5]}$ Sinovektomi esnasında tendon kanlanmasını bozmadan tüm enflame sinoviyum çıkarılır. ${ }^{[15]} \mathrm{Bu}$ esnada tendonda izlenen longitudinal yırtıklar da onarılabilirler.

Evre II'de genellikle Evre I'den daha ileri derecede tendon dejenerasyonu dışında deformiteler de izlenmeye başlar. Bu yüzden bu evrede kombine bir cerrahi tercih edilir. ${ }^{[5]}$ Sinovektomi, debridman ve birincil tamir yanında tendon transferi (özellikle flexor digitorum longus [FDL]), Evans kalkaneus (lateral kolon uzatma) osteotomisi veya kalkaneus mediyal deplasman osteotomisi gibi osteotomiler ve posterior kas grubunun uzatılması gibi seçenekler uygulanabilir.

Tendonun tamamen yırtık (veya dejenere) olduğu ve bulguların ilerlediği Evre II hastalığı olanlarda ise tendon transferi yapılarak hastalıklı olan tendonun neden olduğu ağrının azaltılması ve ayak arkası inversiyon gücünün fonksiyonel bir şekilde sağlanması hedeflenir. [28] Bu amaçla en sık kullanılan tendon anatomik yakınlığından ötürü FDL olmakla beraber fleksör hallusis longus ve peroneus brevisin kullanımı da literatürde tanımlanmıştır.

Tibialis posterior rekonstrüksiyonu sonrasında diz tam ekstansiyonda iken, ayak bileğinde pasif olarak yaklaşık $10^{\circ}$ dorsifleksiyonun elde edilemediği durumlarda, perkütan aşil tendon uzatılması veya Silfverskjöld testine göre gastroknemius gevşetme ihtiyacı ortaya çıkar. ${ }^{[29]}$

Arka ayakta valgus diziliminin eklenmesi durumunda kalkaneusun mediyalizasyonu ile gastroknemius kas grubunun çekme kuvvetini subtalar eklem mediyaline alarak arka ayaktaki varus kuvvetini arttırmak hedeflenir. ${ }^{[15]}$ Varus kurvetine ek olarak rekonstrükte edilen PTT üzerindeki gerilim azaltılır ve mediyal longitudinal ark yüksekliğine katkıda bulunulur. Bu teknikte kalkaneus posteriorundan yapılan transvers osteotomi ile kalkaneus anterior ve posterior olmak üzere iki fragmana ayrılır ve posterior fragman yaklaşık $1 \mathrm{~cm}$ mediyale kaydırıldıktan sonra tespit edilir.

Ayakta pes planovalgus deformitesinin ilerlediği durumlarda lateral kolon mediyal kolona oranla göreceli olarak kısalır. ${ }^{[30]}$ Bu durumda lateral kolon uzatılarak talonaviküler eklemden ön ayağın adduksiyonunun sağlanması ve peritalar subluksasyonun düzeltilmesi hedeflenir. ${ }^{[31]}$ Lateral kolon uzatma Evans tarafindan tarif edilmiş olan distal kalkaneus açık kama osteotomisi ile yapılabileceği gibi kalkaneoküboid eklem distraksiyon artrodezi ile de sağlanabilir. Ancak distraksiyon artrodezi genellikle arka ayak hareketini kısıtlayarak talonaviküler ve subtalar eklemlerdeki stres oranını arttırarak erken dejeneratif değişikliklere yol açabilir.

Arka ayakta mevcut olan deformitenin düzeltilmesine rağmen, ön ayakta supinasyonun devam ettiği ve birinci sıranın yere temas etmediği durumlarda, mediyal kuneiformun plantar fleksiyon açık kama osteotomisi daha dengeli bir temas sağlamak amacıyla ilave edilebilir. ${ }^{[5]}$

Biz kendi pratiğimizde, deformitenin derecesine göre bu tekniklerin bir kısmı veya hepsini birden aynı ayakta uyguluyoruz. Genellikle perkütan aşiloplasti veya gastronemius kas gevşetmesi ile kalkaneus mediyalizasyon osteotomisi ve FDL tendon transferini rutin olarak uyguluyoruz. Bu işlemlerden sonra, talonaviküler örtünümde bariz bir azalma varsa Evans osteotomisini, ayak önü supinasyonunda artış varsa mediyal kuneiform dorsal açık kama osteotomisini işleme ekliyoruz. Erişkinlerde PTT'yi asla feda etmezken, tendonu tamamen dejenere olmuş erişkinlerde bu tendonu yapışma yerinden kesip dejenere kısmı çıkartıyoruz. Spring ligamanda yırtık olup olmadığını mutlaka kontrol ediyor, yırtık varsa gerginleştirerek tamir ediyoruz. Ağrıya neden olan aksesuar naviküler kemik varsa bunu da mutlaka çıkartıyoruz. Aksesuar naviküler kemik varlığı AP grafide bazen talonaviküler örtünümdeki azalmayı gizleyebileceğinden, bu konuda dikkatli olmak gerekmektedir (Şekil 1-3).

Osteotomi veya yumuşak doku prosedürleri yanında subtalar eklemde hareketi engellemeye ve ayağın pozisyonunu korumaya yönelik uygulanan artroereisis pes planusu olan hastalarda kullanılabilecek bir diğer cerrahi tedavi seçeneğidir. Illk olarak Chambers tarafindan ortaya atılan bu fikir daha çok pediatrik 

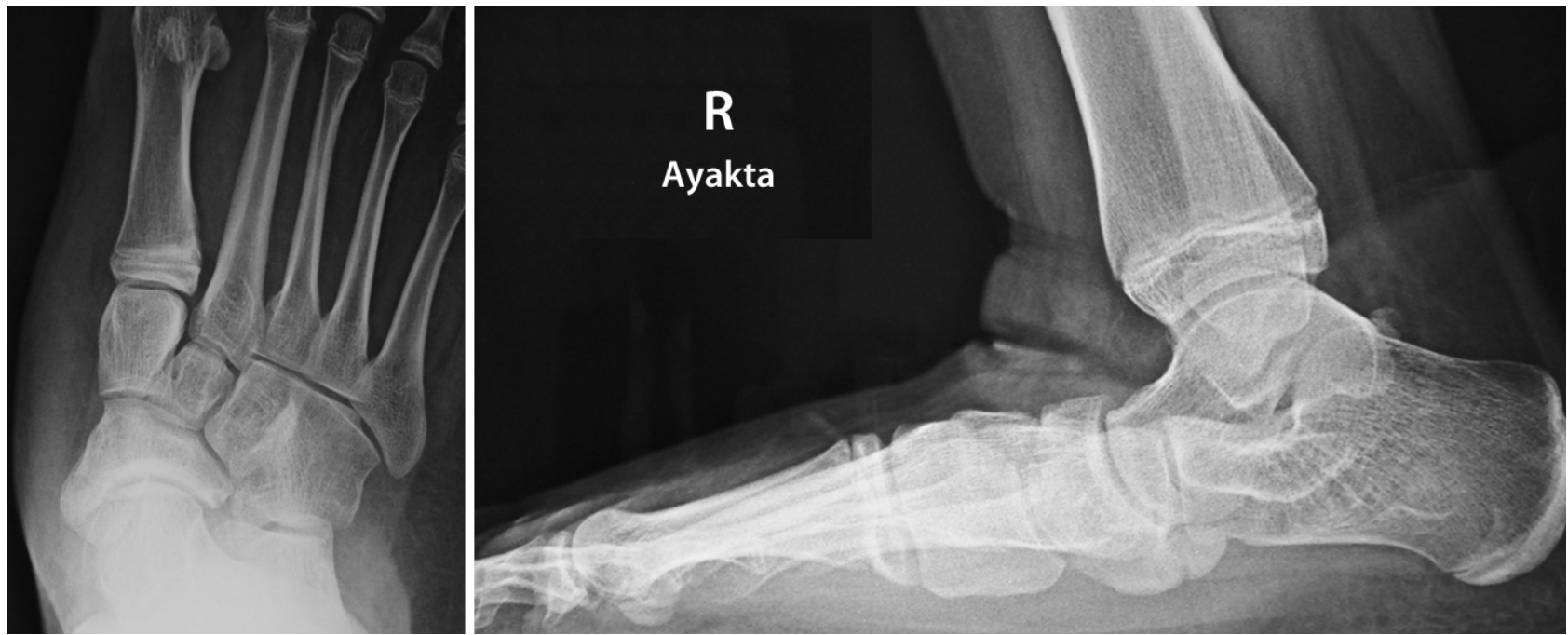

Şekil 1. 15 Yaşında bir kız çocuğunun ameliyat öncesi ayakta basarak çekilmiş AP ve lateral radyografileri (adolesan esnek pes planus). AP grafide aksesuar naviküler kemik görülmekte.
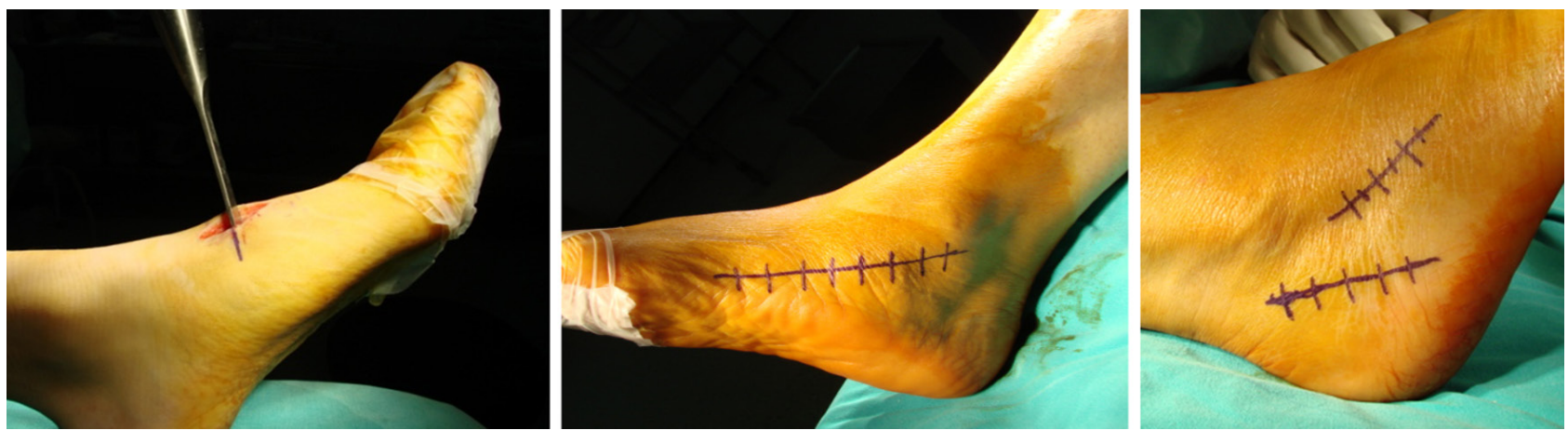

Şekil 2. Mediyal kuneiform osteotomisi, FDL tendon transferi, kalkaneus lateral kolon uzatma ve kalkaneus mediyalizasyon osteotomileri için kullanılan insizyonlar.

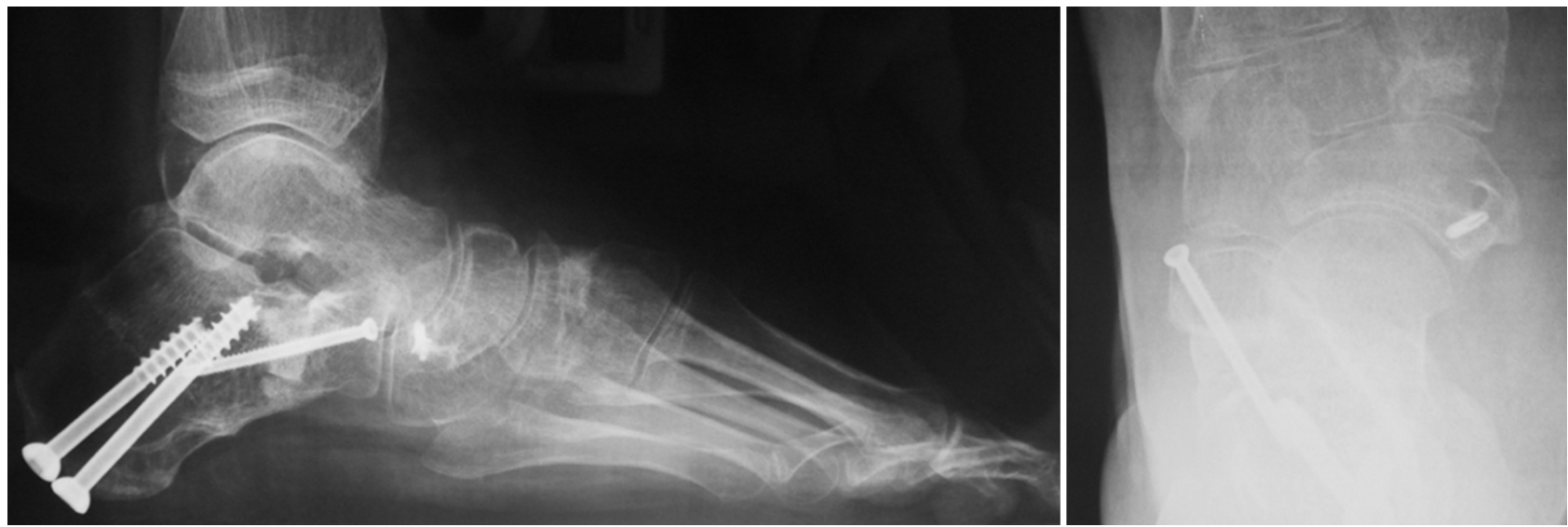

Şekil 3. Resim 1'de radyografileri görülen hastanın perkütan aşiloplasti, lateral kolon uzatma, kalkaneus mediyalizasyon osteotomisi, aksesuar naviküler kemik eksizyonu, FDL tendon transferi ve mediyal kuneiform osteotomisi sonrasında cerrahi sonrası 4. aydaki kontrol radyografileri. 
hastalarda kullanım yeri bulmaktadır. ${ }^{[32]}$ Erişkinlerde kullanımı ise daha çok Evre II hastalığı, özellikle ayak arkasında valgus diziliminin belirgin olduğu Evre IIA hastalığı olanlarda tercih edilmektedir. ${ }^{[33]}$ Kısa iyileşme süresi, kaynamama veya kötü kaynama riski olmaması, daha az invaziv olması gibi özellikleri artroereisisin avantajlarındandır. Bunun yanında sinus tarside ağrı, fazla düzelme, yetersiz düzelme ve pozisyon kaybı görülebilen komplikasyonlardandır. Çocuk hastalarda sıklıkla kullanılmakla beraber erişkinlerde deformitenin esnek olmaması, ayak arkasındaki deformitenin düzeltilmesi sonrasında ön ayaktaki deformitenin ilerlemesi ve subtalar eklem ile orta ayak hastalarıyla kısıtlı kalmaktadır. ${ }^{[34]}$

Pes planus deformitesi sabit olan ve subtalar ile transvers tarsal eklemlerde dejenerasyonu olan hastalarda eklem artrodezi uygulanabilir. ${ }^{[20]}$ İzole subtalar veya talonaviküler eklem artrodezi uygulanabileceği gibi ikili veya üçlü artrodez de uygulanabilir.

İzole subtalar füzyon yalnızca subtalar eklemde sabit bir deformitenin olduğu ve transvers tarsal eklemlerde ağrısız hareketin olduğu durumlarda endikedir.[15] İzole talonaviküler füzyon ise talonaviküler eklemde instabilitenin veya dejeneratif değişikliklerin olduğu durumlarda kullanılır. Talonaviküler eklem artrodezine kalkaneoküboid eklem artrodezinin eklenmesi ikili artrodez olarak tanımlanır ve ilave stabilite sağlar. ${ }^{[20]}$

Rijid, artritik bir pes planus deformitesinin izlendiği hastalarda üçlü artrodez bugün için geçerli bir tedavi seçeneğidir. ${ }^{[35]} \mathrm{Hem}$ deformitenin düzeltilmesi, hem de subtalar, talonaviküler ve kalkaneoküboid eklemlerdeki artrozun tedavisi birlikte sağlanır. ${ }^{[36]}$

\section{SONUÇ}

Erişkin düztabanlıklar, nedeni iyice araştırılmayıp silikon tabanlıklarla geçiştirildiği takdirde bu hastalar yaşlılıkta yürüyemez hale gelebilmekte ve tedavileri daha zor olmaktadır. Bu tip ayak deformiteleri ile karşılaşıldığında hemen MR istemektense ayakta dik dururken çekilmiş direkt röntgen grafilerini istemek çok daha faydalıdır. Semptomatik hastalarda, eğer morbid obesite, aşırı sigara tüketimi, nonkoopere hasta gibi kontrendikasyon yoksa, cerrahiden kaçınmamak gerekir. Uygun cerrahiye, altta yatan neden ve deformitenin derecesine göre karar verilmelidir.

\section{KAYNAKLAR}

1. Lee MS, Vanore JV, Thomas JL, Catanzariti AR, Kogler G, Kravitz SR, Miller SJ, Gassen SC; Clinical Practice Guideline Adult Flatfoot Panel. Diagnosis and treatment of adult flatfoot. J Foot Ankle Surg 2005;44(2):78-113.
2. Vanderwilde R, Staheli LT, Chew DE, Malagon V. Measurements on radiographs of the foot in normal infants and children. J Bone Joint Surg Am 1988;70(3):407-15.

3. Yeagerman SE, Cross MB, Positano R, Doyle SM. Evaluation and treatment of symptomatic pes planus. Curr Opin Pediatr 2011;23(1):60-7. CrossRef

4. DeYoe BE, Wood J. The Evans calcaneal osteotomy. Clin Podiatr Med Surg 2005;22(2):265-76.

5. Haendlmayer KT, Harris NJ. Flatfoot deformity: an overview. Orthopaedics and trauma 2009;23(6):395-403.

6. Funk DA, Cass JR, Johnson KA. Acquired adult flatfoot secondary to posterior tibial tendon pathology. J Bone Joint Surg Am 1986;68(1):95-102.

7. Petje G, Steinböck G, Landsiedl F. Arthrodesis for traumatic flatfoot. Tarsometatarsal and medial longitudinal arch fusion by inlay grafting, 11 feet followed for 1.5 years. Acta Orthop Scand 1996;67(4):359-63.

8. Masterson R, Mulcahy D, McElwain J, Mclnerney D. The planovalgus rheumatoid foot - is tibialis posterior tendon rupture a factor? BrJ Rheumatol 1995;34(7):645-6.

9. McLaren Ca, Wootton JR, Heath PD, Jones $\mathrm{CH}$. Pes planus after tibial osteotomy. Foot Ankle 1989;9(6):300-3.

10. Scartozzi G, Kanat IO. Diabetic neuropathy of the foot and ankle. J Am Podiatr Med Assoc 1990;80(6):298-303.

11. Cohen BE, Davis WH, Anderson RB. Success of calcaneonavicular coalition resection in the adult population. Foot Ankle Int 1996;17(9):569-72.

12. Mosca VS. Flexible flatfoot in children and adolescents. J Child Orthop 2010;4(2):107-21. CrossRef

13. Hicks $\mathrm{JH}$. The mechanics of the foot. II. The plantar aponeurosis and the arch. J Anat 1954;88(1):25-30.

14. Jack EA. Naviculo-cuneiform fusion in the treatment of flat foot. J Bone Joint Surg Br 1953;35-B(1):75-82.

15. Trnka HJ. Dysfunction of the tendon of tibialis posterior. J Bone Joint Surg Br 2004;86(7):939-46.

16. Monto RR, Moorman CT III, Mallon WJ, Nunley JA 3rd. Rupture of the posterior tibial tendon associated with closed ankle fracture. Foot Ankle 1991;11(6):400-3.

17. Borton DC, Saxby TS. Tear of the plantar calcaneonavicular (spring) ligament causing flatfoot. A case report. J Bone Joint Surg Br 1997;79(4):641-3.

18. Beals TC, Manoli A 2nd. An unusual cause of posterior tibial tendon degeneration. Foot Ankle Int 1998;19(3):177-9.

19. Kohls-Gatzoulis J, Angel JC, Singh D, Haddad F, Livingstone J, Berry G. Tibialis posterior dysfunction: a common and treatable cause of adult acquired flatfoot. BMJ 2004;329(7478):1328-33.

20. Squires NA, Clifford CL. Posterior tibial tendon dysfunction. Oper Tech Orthop 2006;16:44-52.

21. Pomeroy GC, Pike RH, Beals TC, Manoli A 2nd. Acquired flatfoot in adults due to dysfunction of the posterior tibial tendon. J Bone Joint Surg Am 1999;81(8):1173-82.

22. Myerson M, Solomon G, Shereff M. Posterior tibial tendon dysfunction: its association with seronegative disease. Foot Ankle 1989;9(5):219-25.

23. Bluman EM, Title $\mathrm{Cl}$, Myerson MS. Posterior tibial tendon rupture: a refined classification system. Foot Ankle Clin 2007;12(2):233-49.

24. Raikin SM, Winters BS, Daniel JN. The RAM classification: a novel, systematic approach to the adult-acquired flatfoot. Foot Ankle Clin 2012;17(2):169-81. CrossRef 
25. Satoru O. Post-traumatic flatfoot. Orthopaedic Surgery and Traumatology 2004;47(10):1167-75.

26. Thorpe SW, Wukich DK. Tarsal coalitions in the adult population: does treatment differ form the adolescents? Foot Ankle Clin 2012;17(2):195-204. CrossRef

27. Marzano R. Functional bracing of the adult acquired flatfoot. Clin Podiatr Med Surg 2007;24(4):645-56.

28. Aronow MS. Tendon transfer options in managing the adult flexible flatfoot. Foot Ankle Clin 2012;17(2):205-26. CrossRef

29. Coetzee JC, Castro MD. The indications and biomechanical rationale for various hindfoot procedures in the treatment of posterior tibialis tendon dysfunction. Foot Ankle Clin North Am 2003;8(3):453-9.

30. Roche AJ, Calder JD. Lateral column lengthening osteotomies. Foot Ankle Clin 2012;17(2):259-70. CrossRef

31. Zaw H, Calder JD. Operative management options for symptomatic flexible adult acquired flatfoot deformity: a review. Knee Surg Sports Traumatol Arthrosc 2010;18(2):13542. CrossRef
32. Chambers EF. An operation for the correction of flexible flat feet of adolescents. West J Surg Obstet Gynecol 1946;54:77-86.

33. Fernández de Retana $P$, Alvarez F, Bacca G. Is there a role for subtalar arthroereisis in the management of adult acquired flatfoot? Foot Ankle Clin 2012;17(2):271-81. CrossRef

34. Soomekh DJ, Baravarian B. Pediatric and adult flatfoot reconstruction: subtalar arthroereisis versus realingment osteotomy surgical options. Clin Podiatr Med Surg 2006;23(4):695-708.

35. Bennett GL, Graham CE, Mauldin DM. Triple arthrodesis in adults. Foot Ankle 1991;12(3):138-43.

36. Ahmad J, Pedowitz D. Management of the rigid arthritic flatfoot in adults: triple arthrodesis. Foot Ankle Clin 2012;17(2):309-22. CrossRef 